\title{
Research on Spare Parts Management System of Converter Substation Based on Internet of Things
}

\author{
Jian-Xin GU ${ }^{1, a}$, Di DAI ${ }^{1, a}$, Yan-Wen WANG ${ }^{1, a,{ }^{*}}$, Hao PENG ${ }^{1, a}$, Yu-Ting FU ${ }^{1, a}$
}

${ }^{1}$ State Grid Hubei electric power company maintenance company High voltage ac and dc transportation center, yichang,china

\section{a272069680@qq.com}

"Yan-Wen WANG

\begin{abstract}
Keywords: Spare Parts, Management Style, Data Control, Internet of Things
Abstract.In order to make up for the management defects of the spare parts management mode in the converter substation, combining the thinking mode of the internet of things to improve the management mode of spare parts, and realize the management of spare parts and spare parts to further enhance the intelligent degree of substation management, the intelligent management system of spare parts is put forward. Based on the C \# development platform and database SQL Server 2005, the internet of things RFID technology and the idea of the internet of things to design and develop the data management system of spare parts for substation, some advantages have achieved by the replacement of traditional management. It improves the management efficiency of spare parts, and promotes the completion of the converter substation construction and effectively safeguards the management system. It is also able to monitor and manage spare parts in an orderly and accurate way, improve the reliability of management, and save costs.
\end{abstract}

\section{Introduction}

Power spare parts are important power material, and to strengthen spare parts management is to ensure the safe and stable production of power enterprises. They are the focus of the state grid company. The Yidu reach converter station, Gezhouba converter station, Longquan converter station, Jiangling converter station and Tuanlin converter station are under the control of Yichang DC power transmission and inspection center, which is responsible for the unified management of 5 station spare parts for primary and secondary storage. The management mode of spare parts is still the traditional written management mode, and the efficiency and reliability are difficult to meet the actual management needs. In the power system, it not only relates to the cost management of the enterprise, but also closely related to the safety production management of the enterprise. Therefore, in the process of equipment management, spare parts management should be given enough attention.

At present, the intensive, life cycle and the application of the Internet of things are gradually adopted in the domestic power enterprises to manage the spare parts [1]. The document [2] introduces that the enterprises in the energy sector and enterprises in China have adopted intensive material management mode at present. In the power enterprises, the southern power grid company and the national grid company have changed the integration of material management into a new idea of modern material management. The document [3] expounds the concept of life cycle management, and introduces the application of the method of life cycle management in domestic power enterprises. Some electric power enterprises improve their equipment comprehensive management level through this management application. The management system of many large companies in foreign countries has realized the more mature intensive, especially for material management, there are many applicable software packages in the material management work [4]. The document [5] recognizes that the life cycle theory of power equipment divides the life cycle of power equipment into several important stages, such as purchase, operation, maintenance, repair, update, scrap and so on. And it regards each stage of the equipment as the process of related, not isolated existence. The management method has been applied in the substation, power distribution system, power generation system and so forth.

The spare parts management system developed in this paper is based on the modern internet of 
things information technology and information perception and recognition technology. It combines with the management ideas and intensive and life cycle management concept of the Internet of things.

\section{Spare Parts Management of Substation}

\section{Spare Parts for Electric Power}

Spare parts can be divided into the first kind of spare parts (accident spare parts) and the second kind of spare parts (alternate spare parts and spare parts) according to their important and difficult degree of processing [6]. Management of spare parts is the main content of equipment maintenance and resource management. It is also an important part of power plant maintenance and unscheduled maintenance. Only scientifically sound reserves and efficient management can ensure the quality of power planning and unplanned tasks while ensuring economic performance [7].

\section{Application of the Internet of Things Technology}

The Internet of things is the use of product electronic code EPC, radio frequency identification technology, through the network to achieve at any time, any place for the identification and management of any article. That is the interconnection and communication of the goods. Through the application of the internet of things technology, it can realize the management data of spare parts and the information binding of spare parts, and change its management mode to achieve the goal of lean management combined with database reading and writing, that is, efficient, economic and "paperless".

The interconnection data are the automatic identification technology of communication through radio wave to communicate, namely RFID technology. The spare parts management system developed in this paper adopts H47 RFID UHF RFID tag. The UHF RFID tag can realize the 3D full range of signal range with fast data transmission, which greatly reduces the recognition error and recognition failure rate of spare parts.

QR code matrix two-dimensional code two-dimensional code technology has the advantages of high density, large capacity, high level security and so on, in particular, it has the characteristics of error correction function. The two-dimensional bar code can be read correctly because of the local damage caused by the perforation, stained and so on. Therefore, use of QR Code matrix and twodimensional code combined with RFID can make the information management of the spare parts management system diversified, and ensure the reliability of information identification.

\section{Optimization of Management Mode}

1) Traditional Management Mode The traditional management model can not meet the needs of science, there are the following problems: First, the information is scattered, the information "isolated island" is serious, and it is easy to cause the blind purchase of spare parts. Second, unreasonable quota measurement makes the types of spare parts storage and the establishment of reserve quota unscientific. Third, the concept of management personnel has not changed, "multi standby less patient" error thinking throughout the daily operation and maintenance work. Fourth, spare parts reserve surplus, so many spare parts have not been collected and need to scrap. Finally, the imperfect management system causes additional time cost, such as obtaining spare parts information for a long time.

2) New Management Model The new management method realizes the combination and application of network and computer technology, through the assistant of management system, can more effectively manage the spare parts in an orderly and accurate inventory management, record the use of spare parts efficiently and accurately, and optimize the inventory management to the maximum extent. Showed as Picture 1.

3) Information Management, Intensification and Transactions The new management mode, based on the network communication environment of CaiTuo substation, establishes the information interconnection foundation, and manages the dispersed geographical objects to realize 
the intensification of information management through the information base. It cannot only speed up the efficiency of information search, but also enhance the order and convenience of information management. On the basis of information intensification, it introduces the application of the thinking and technology of the internet of things, and makes the spare parts entities to recognize the objects, attribute information, related personnel and the use of records closely and quickly obtained information through information recognition. Show at picture 2 .

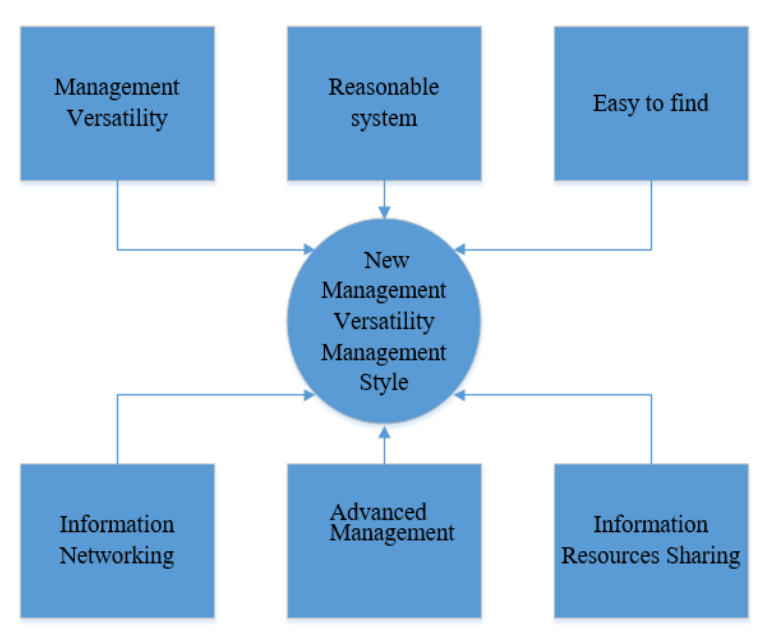

Picture 1 Characteristics of New Management Style

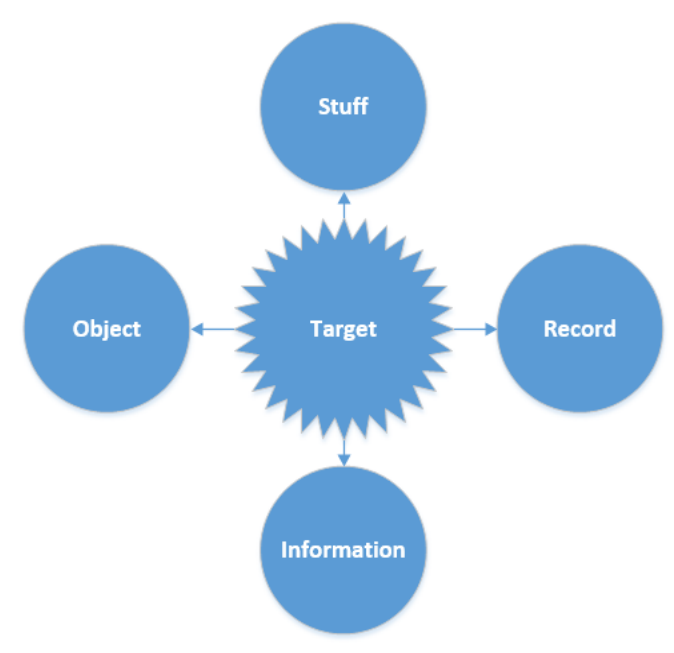

Picture 2 Information Management

\section{System Design}

\section{System Architecture}

The overall framework of the spare parts management system infrastructure is shown in figure 3 . The application layer covers all the application modules that interact with the user directly, the data management and data control module to achieve the functional requirements of data control. It establishes the electronic journal of spare parts, and achieves data information tracking and data reading and writing. User management and privilege distribution service module of the support layer can realize centralized and orderly management, through the face recognition to complete user authentication, and automatically assign corresponding permissions according to the user level. The data layer contains the dynamic and static database of spare parts, providing the data foundation for the application layer and the supporting layer. It is an indispensable part of the system architecture.

\section{System Network Structure}

As shown in figure 4, the spare parts management system is a C/S integrated management system, which can be divided into two parts according to logic, one is the client application used in the spare parts library, and the other is the data server.

\section{Database Structure}

The management system uses the tool SQL Server 2005 to build the database to meet the necessary extensibility, practicability and maintainability. In the database, the data tables of spare parts, the type of spare parts, the records of the lead, the supplement, the record and the user's data sheets are established.

\section{Development of System Function Module}

Spare parts management system according to the actual management needs of spare parts is divided into data management, quantity control, electronic report, label calculation, information perception and recognition. 


\section{Data Management Module}

Spare parts management system will be all spare parts of the attribute information into the database for grouping, sub - area unified management. When the user needs to inventory, it can be easy and quick. It realizes the spare parts database closed - loop management mode. According to the unique digital certification id of every spare part, this paper realizes the fast identification and positioning of spare parts by RFID sensor / 2 - D image handheld reader, and realizes the closed-loop "paperless" management of the whole process of the spare parts collection, replenishment and storage.

1)Data Import / Export

The result of data export is shown in the picture 5 .
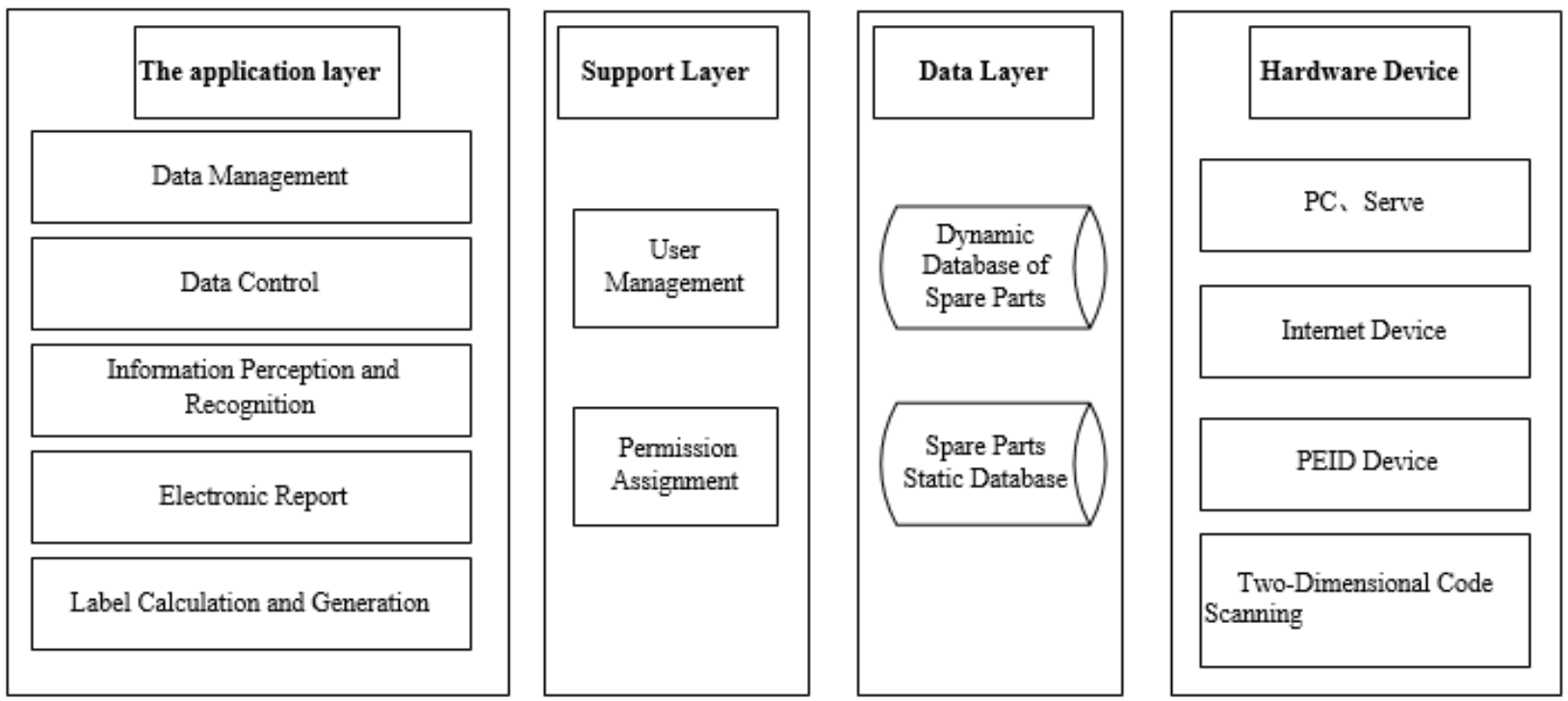

Picture 3 the Structure of the System
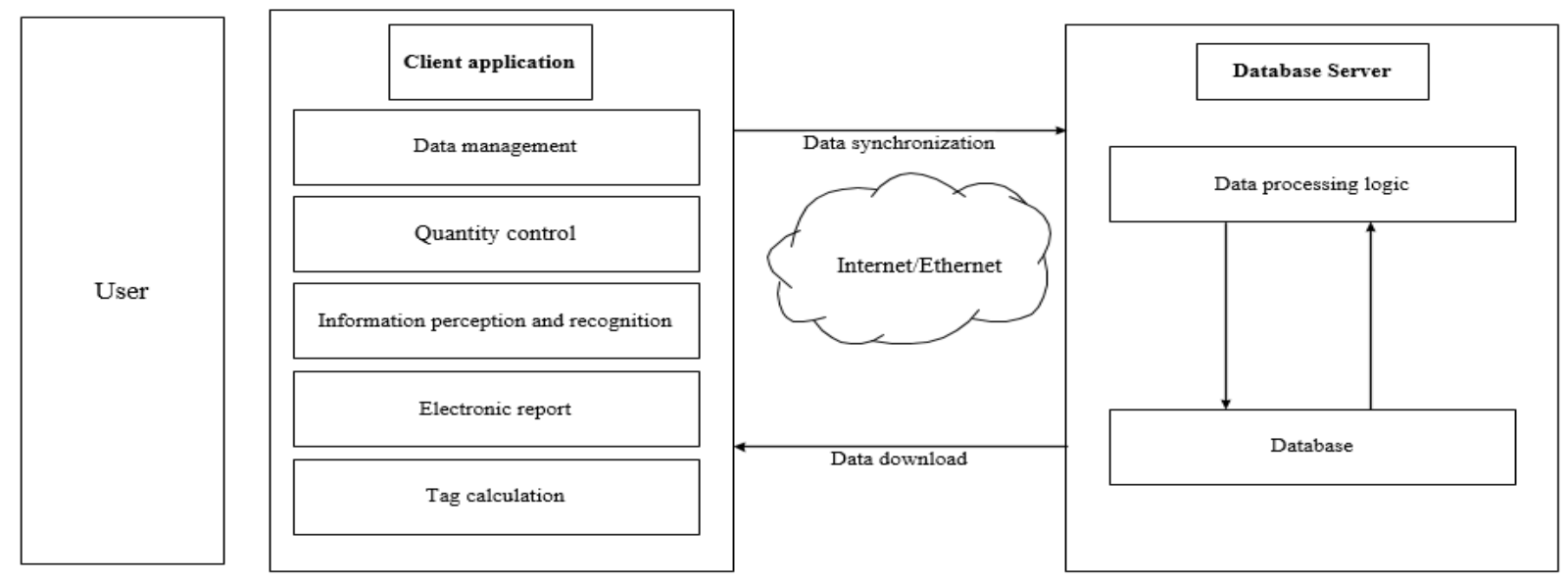

Picture 4 System Network Structure 


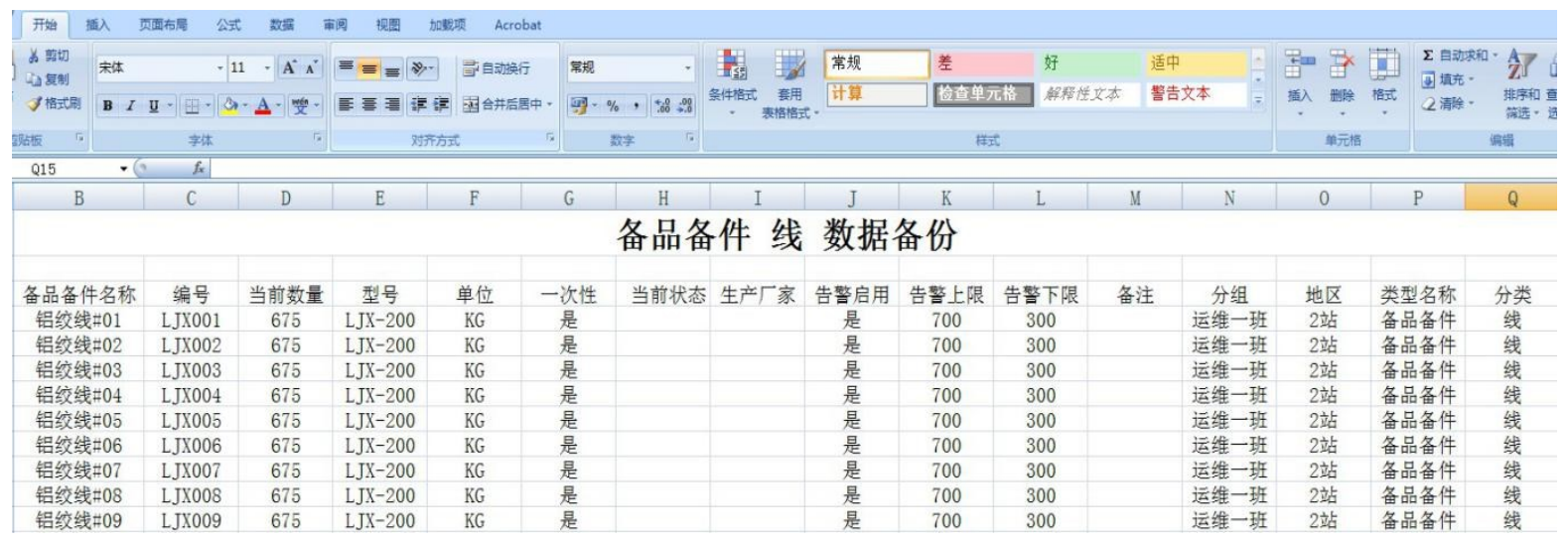

Picture 5 Data export of spare parts

2)Collecting and Replenishing

The user only needs to use two-dimensional image handheld reader to carry out the twodimensional code label identification of spare parts, and the editing work event can complete the batch receipt. The collecting operation is shown in figure 6 .

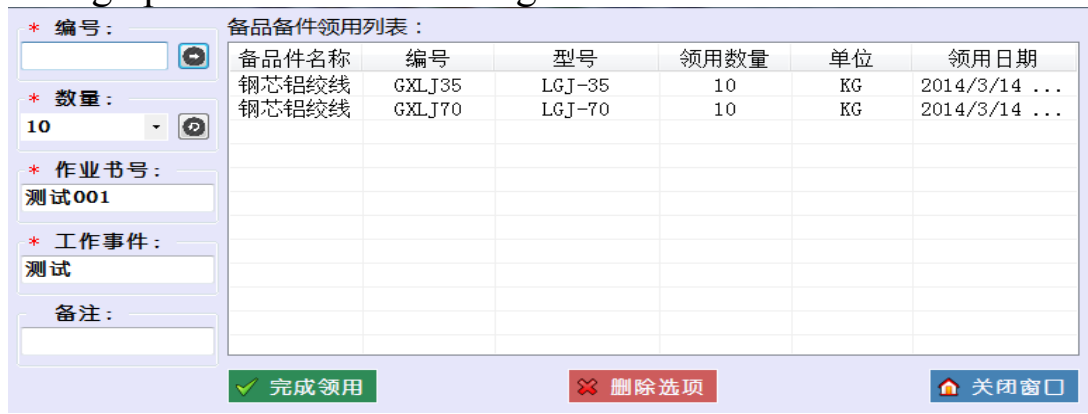

Picture 6 requisits interface

The system can also monitor the recognition of the RFID tag of the spare parts in time. When the data are read, the data will be read and written without affecting the main thread, and the records of automatic storage and delivery will be completed.

\section{Quantity Control Module}

This module can avoid the shortage of spare parts due to the negligence of management personnel, the quantity of spare parts is not timely or excessive, and the reminder history will be included in the database to provide some data basis for the risk assessment of spare parts. In addition, the data monitoring of spare parts will be automatically opened with the main thread. If spare parts items with insufficient stock and exceeding limit are found, the indication shall be displayed in the way of icon flashing. This cannot only prevent the on-site operation and equipment maintenance requirements of the shortage of spare parts, but also effectively manage the supply and demand of spare parts, and avoid the waste of resources caused by some long-term excess spare parts.

\section{Electronic Report Module}

The standardized electronic report is designed and adjusted according to the management requirements of spare parts. The module can assist managers to easily manage the archive data and the use of spare parts, and can print the required report data by one key printing. At the same time, users can select the time period for the screening of spare parts records. Sufficient authority of the user can eliminate the old record data no longer needed.

\section{Tag Calculation Generation Module}

The open source QR code matrix $2 \mathrm{~d}$ code computing component is referenced to complete the processing and calculation of $2 \mathrm{~d}$ barcode information flow for spare parts information. This 
function can provide users to create spare parts identification tags, label editing, label saving, label printing and other operations. The interface is shown in picture 7.

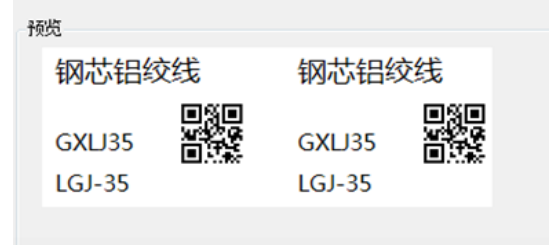

Picture 7 Generation of Label for Spare Parts

\section{Information Perception and Recognition Module}

It uses facial recognition devices to face efficient algorithm, connected by TCP/IP protocol and RJ45 interface and spare parts management system. After the user finishes on the face at the same time, it makes data comparison of multifaceted background user ID, from finding the local database and the server database authentication information.

\section{Jiangling Converter Station Test Runing}

After the test development is completed, the spare parts management system has been installed in Jiangling converter station. Through the field test run situation: The management system is not only in the management of basic elimination of the existing traditional management mode, in accordance with the specific requirements of standardization and intelligent construction, reduce the workload of managers, but also has a significant role in the improvement of the overall efficiency.

Specific performance in the following aspects:

1) It eliminates the problems caused by the traditional management model due to the factors such as the lack of timely inventory of spare parts and the negligence of managers, etc.

The management system of spare parts has records and real-time monitoring of the situation of every spare part, including the quantity of spare parts in the library, quota allocation, storage location, location, the collecting person and use of spare parts and so on. When the spare parts in the system account exceed the quota allocation or lower than the allocation requirements, the management personnel are reminded in the way of sound and light alarm, and the list of spare parts that need to be controlled can be viewed independently. In improving the reliability of the use and management of spare parts, it also makes the quota management of spare parts more rigorous and timely.

2) Improve the management efficiency of the spare parts of the substation. After introducing the spare parts management system, the collecting and management of spare parts is simpler and more convenient. In the collection and return of spare parts, we simply need to use two-dimensional label identification equipment or RFID equipment to identify the spare parts identification tags. This greatly shortens the time of receipt and return, and the whole process takes a few minutes to ensure the efficiency of the spare parts in operation and maintenance.

As can be seen from Table 1, the spare parts management system saves a lot of time and greatly improves the efficiency of the spare parts. It provides a strong time guarantee for the spare parts to arrive at the job site on time.

It has effectively promoted the improvement of the converter station and effectively ensured the management system. After using this system, the manual record Ledger is reduced and the electronic ledger is used instead of the paper ledger. Using electronic ledger instead of paper ledger, in the system, only one click printing, you can get all the required work information returned. It is not only convenient access and easy to save, to ensure the consistency of the table, card, "the more, save time and manpower, the real reached a burden for the team, more convenient management to check ledger records. It can also quickly lead the use of spare parts, shorten the time required for the operation and maintenance of the operation and maintenance, to a certain extent to promote the stability of the role. 
Table 1. Comparison of collecting time between traditional management and management system

\begin{tabular}{ccccccc}
\hline Management Model & Tab & $\begin{array}{c}\text { Confirmation } \\
\text { list }\end{array}$ & $\begin{array}{c}\text { Register } \\
\text { List }\end{array}$ & $\begin{array}{c}\text { Checking } \\
\text { condition }\end{array}$ & $\begin{array}{c}\text { Confirmed } \\
\text { signature }\end{array}$ & $\begin{array}{c}\text { Total } \\
\text { time }\end{array}$ \\
\hline $\begin{array}{c}\text { Traditional } \\
\text { Management }\end{array}$ & 5 & 2 & 5 & 5 & 3 & 20 \\
New Management & 0 & 2 & 1 & 2 & 1 & 6 \\
\hline
\end{tabular}

Note: This table is for the normal use of spare parts time.(Unit: Min)

4)It standardizes the management of spare parts, and also regulates the behavior of administrators. After using this system, it has realized the intelligence of the spare parts to be used and returned. Perfect information needs only a simple recognition can be completed ledger records and data. It also shortens the spare parts receiving, return time, improves work efficiency, and reduces the burden on users. Administrators can also regulate their behavior. The system is simple, fast, easy to learn, practical and operational, and the administrator will be able to operate the spare parts according to the process. When spare parts are used and returned, face recognition is used instead of manual signature, which saves the workload and makes the identity record more accurate and accurate. The spare parts management system sets the operational authority, monitors the user's situation in real time, and avoids the risk reasonably. Each spare part is recorded in the system, and can query its basic situation and use.

\section{Conclusion}

Based on the idea of internet of things, this paper develops the spare parts management system based on the basic environment of the converter substation, and completes the expected target in combination with SQL Server database. It effectively reduces the daily spare parts management workload of substation, achieves the purpose of rapid management and "paperless" management, and improves the management efficiency of spare parts management. It also strengthens the management reliability of the management, increases the identification amount of spare parts, makes the records reach the close relationship between the operator and the operation and the operation events, and indirectly guarantees the orderliness and reliability of the management work.

With the improvement of management requirements in the future, the data management system can be updated to function, expand the database size, and better realize the concept of the three layers of the internet of things, so that the system has stronger applicability, flexibility, scalability and innovation.

\section{References}

[1] Wang Yisheng Wang Feng Zero Inventory Theory in Supply Chain Management Mode and its Application in Enterprises [J] Logistics Technology 2002(9):1

[2]Formoso, C.T. and Soibelman, L. (2002) Material Waste in Building Industry: Main Causes and Prevention. Journal of Construction Engineering and Management, 128, 316-325.

[3] Sun Yixin Practice and Enlightenment of Life Cycle Management of Assets of British National Grid Corporation [J] Prices Monthly 2011, 11(22): 91-94.

[4] Zhangmeng Research on the Implementation Strategy of Electronic Bidding of Chinese Electric Power Enterprises under the Background of Material Intensification [ D ][ Master's degree thesis] Beijing: Beijing University of Posts and Telecommunications

[5]Shimakage, T., Wu, K., Kato, T. Okamoto, T. and Suzuoki, Y. (2003) Life-Cycle-Cost 
Comparison of Different De- gradation Diagnosis Methods for Cables. Properties and Applications of Dielectric Materials, 990-993.

[6] ZhangBing Research on Storage Management of Spare Parts for $750 \mathrm{KV}$ Power Grid in Northwest Power Grid Corporation [Master's degree thesis] Yang Ling: Northwest Agriculture and Forestry University of Science and Technology, 2014: 7-9.

[7] Zhou Guliang Discussion on Optimization Management of Spare Parts in Power Enterprises [J]. Shanghai Electric Power 2008(6): 576-579. 